\title{
O conflito entre o plano de expressão e conteúdo na poesia de Glauco Mattoso
}

\author{
Fabiano Garcia Baltazar da Silva ALONSO (USP) \\ e Patrícia Amorim da SILVA (USP)
}

RESUMO: O objetivo desse artigo é verificar a aplicação do percurso gerativo do sentido junto ao plano de expressão e de conteúdo, apoiado no princípio isomórfico de Hjmeslev. Como exemplo, escolhemos a poesia de Glauco Mattoso, por se tratar de um texto poético, é bastante evidente a motivação entre os dois planos.

PALAVRAS-CHAVE: semiótica; poesia; transgressão.

RÉSUMÉ: L'objectif de cet article, est vérifier l'application du parcours gerativo du sens près du plan d'expression et de contenu, soutenu en principe isomorfique de Hjmeslev. Comme exemple, nous choisissons la poésie de Glauco Mattoso. Vu que, dans le texte poétique, est suffisamment évidente la motivation entre les deux plans.

MOTS-CLÉS: sémiotique; poésie; transgression. 


\section{Introdução}

O ponto de partida deste trabalho é o modelo semiótico desenvolvido por A. J. Greimas e colaboradores, a partir das propostas de Hjelmslev em Prolegômenos a uma teoria da linguagem, baseado nos princípios isomórficos entre os planos de expressão e conteúdo.

Nessa semiótica dita greimasiana, têm-se descrito por meio do percurso gerativo a construção de um modelo que busca sistematizar e compreender o sentido, partindo para tanto, do chamado plano de conteúdo. Apoiado nos níveis fundamental, narrativo e discursivo, esse modelo explica como o sentido é organizado, permitindo ao semioticista estudar e tomar o processo de significação como objeto de estudo.

O que propomos é aplicar esse mesmo modelo de definição de sentido, junto ao plano de expressão. Uma vez que, segundo Hjelmslev, cada plano possui duas instâncias de análise: existindo uma forma e uma substância do conteúdo, do mesmo modo que há uma forma e uma expressão da expressão. Devemos entender, portanto, substância da expressão, como sendo o som; e substância do conteúdo, os conceitos. Do mesmo modo que, a forma da expressão deve compreender as diferenças fônicas; a forma do conteúdo deve representar as oposições semânticas. Ou seja, para o lingüista "é em razão da forma do conteúdo e da forma da expressão, e apenas em razão delas, que existem a substância do conteúdo e a substância da expressão, que surgem quando se projeta a forma sobre o sentido, tal como um fio esticado projeta a sua sombra sobre uma superfície continua" (Hjelmslev, 1975: 61).

Ora, uma vez aplicado o percurso que defini o sentido para os dois planos da linguagem, temos a possibilidade de seguir em direção ao plano de expressão, verificando como é possível sistematizar, apoiado na isomorfia entre os dois planos, a construção de um sentido sonoro, de maneira a colocá-lo em função do conteúdo.

$\mathrm{O}$ que se pretende com este trabalho, é justamente realizar essa primeira investigação, abrangendo por meio do percurso gerativo do sentido, o plano de expressão e de conteúdo; justificando assim, uma correlação entre ambos. Para isso escolhemos como corpus, o texto poético, mais especificamente, a poesia; verificando que a motivação entre os planos, neste caso, torna-se melhor evidenciada.

\section{A Bio / grafia do autor}

O poema abaixo, foi retirado da coletânea Poesia Digesta, que reúne grande parte dos sonetos escritos por Glauco Mattoso, desde o início de sua carreira artística. Sempre voltado à cultura underground, Glauco é apontado por manter uma estreita relação com o grupo dos poetas ditos marginais, justamente por trazer sua obra à margem do cânone literário brasileiro.

Ainda nos anos 70, participou da luta contra a censura artística, abordando temas como: sadomasoquismo, perversão, escatologia, fetichismo e outros. Tomado por alguns críticos pela alcunha de poeta "maldito" ou "pervertido", Glauco vê a poesia como uma forma de desabafo pessoal e ao mesmo tempo coletivo. Tudo aquilo que parece formalmente desprezível - como o palavrão ou a gíria - e tematicamente 
polêmico - como a violência ou a perversão - temas repugnantes para determinada cultura: qual? - tem uma função poética, segundo o autor.

Escrevendo sob forma de soneto, onde trabalha incessantemente com o ritmo e a métrica, o poeta diz preferir a forma fixa ao verso livre, uma vez que passou a valorizar a palavra "medida" após ter sido vítima de um glaucoma - daí a ironia com o próprio apelido - que veio tirar-lhe a visão.

\section{Desforrado}

Bem feito! Quem mandou me ler? Agora vai ter que me engolir com casca e tudo! E mesmo quando, em parte, me desnudo, quem prova sente nojo e cospe fora.

"Bem feito!" (é o que se diz ao cego) "Chora!"

Eu choro, mas em vez dum pranto mudo converto o desabafo em verso agudo, tão grave quanto um frade que não cora.

Sem papas, meus buracos escancaro e os olhos dos leitores esbugalho ao verem que a derrota vendo caro.

E a quem acha bulhufas o que valho das tralhas mais baratas sou avaro de modo a indecifrar-lhe meu trabalho.

\section{Plano de Conteúdo}

Nesse poema, o ponto-chave da análise é a transgressão poética. Basta notar que o soneto surge como uma espécie de vingança, uma vez que "Desforrado" significa vingado, recompensado. É, portanto, numa atitude metalingüística que Glauco Mattoso trata aqui a questão do fazer poético, onde por meio da própria poesia, ele explica o modo e o motivo pelo qual escreve o soneto. Verificamos inicialmente que o sujeito narrativo, marcado no em primeira pessoa, deixa claro não estar disposto a querer entrar em conjunção com os valores tomados pelo sujeito enunciatário - realizado no discurso pela figura de um leitor avesso aos temas não-convencionais: (Bem feito! Quem mandou me ler? Agora / vai ter que me engolir com casca e tudo!). Há, portanto, um conflito de valores no plano de conteúdo. O sujeito enunciador toma esse modelo de sujeito enunciatário como sendo responsável, por colocar o seu fazer poético à margem da literatura dita canônica. Isso, pelo fato de julgar transgressiva a figura do poeta, razão pela qual ele o "cospe" fora.

Ora, percebemos existir dois pontos de vista diferentes sobre o mesmo objeto de valor, que no caso é a poesia: de um lado o enunciador defendendo seu fazer poético ("Sem papas, meus buracos escancaro"), e do outro, um determinado tipo de leitor que 
tem seus olhos esbugalhados ao ler o poema. Parece evidente que o enunciador procura nos remeter ao campo da transgressão, do fetichismo, do erótico, em que escancarar os "buracos" justifica retratar abertamente as fantasias, trazer à tona por meio da poesia, aquilo que muita vez só é discutido em ambientes fechados ou restritos. Ou seja, o fato do leitor ter os olhos esbugalhados ao ler o soneto, confirma, portanto, o rompimento do enunciador com a barreira da moral conservadora, que considera como não-adequado, abordar assuntos tidos como "polêmicos" ou de gosto duvidoso. É sob esses dois aspectos distintos que o soneto irá se caracterizar.

Em nível fundamental, encontramos a categoria semântica em que esses valores estão articulados em transgressão versus integração. Como o poema incide sobre dois valores opostos, devemos tomar o cuidado de analisar a forma como cada uma deles é sensibilizado, de acordo com o ponto de vista adotado. Se tomarmos nossa análise a partir do sujeito enunciador, trata-se da figura de um poeta em disjunção com os valores representativos da integração. Em contrapartida, se partirmos do ponto de vista do sujeito enunciatário, trata-se da figura de um tipo de leitor que coloca o fazer poético do sujeito enunciador em conjunção com os valores representativos da transgressão.

Neste caso, temos duas vozes diferentes retratadas com timias distintas. A transgressão no primeiro momento é sensibilizada disforicamente e a integração como eufórica, ao passo que na situação seguinte, temos uma inversão desses valores: a transgressão é sensibilizada euforicamente e integração de modo disfórico. Vemos a afirmação da transgressão aparecer no verso: "Bem feito!" (é o que se diz ao cego) "Chora!" / Eu choro, mas em vez dum pranto mudo / converto o desabafo em verso agudo (...). Entretanto, a negação surge no desabafo do próprio poeta, que ao invés de consentir um pranto mudo, transforma-o em "verso agudo", lexicalizando, assim, a metáfora de um grito de liberdade, em que o agudo sugere um som capaz de romper as barreiras do convencional e de afirmar, portanto, a transgressão (marginalidade).

É por meio então de uma linguagem direta, marcada pela ironia, que o leitor percebe a construção de uma poesia bastante peculiar. No plano de expressão vê-se uma estrutura formal, onde o soneto se constitui a partir de versos decassílabos, seguindo o padrão de rimas: abba abba cdc dcd. Em contrapartida, no plano de conteúdo, observase uma marginalidade que quer se impor. Existe, portanto, uma relação de transgressão (plano de conteúdo) e integração (plano da expressão) que permeia toda a poesia. Nesse aspecto, verificamos uma relação intertextual, na medida em que o soneto sempre foi empregado pela tradição literária para abordar temas elevados e nobres, justificando, assim, o enunciador neste caso, a lançar mão de uma forma clássica, para tentar adentrar no âmbito do cânone. Porém, tratando de temas considerados marginais e cotidianos.

Em relação as categorias: semântica, fórica e tensiva, onde reúnem-se as dimensões do inteligível e do sensível, o poema segue o percurso (não- integração / nãodisforia / distenção / parada da parada) $\rightarrow$ (transgressão / euforia / relaxamento / continuação da continuação) $\rightarrow$ (não- transgressão / não-euforia / contenção / parada da continuação). Uma vez que o soneto surge em resposta ao sujeito enunciatário, nega-se então a transgressão e o sujeito narrativo passa a protestar escrevendo o próprio poema, 
ou seja, assumindo um estado de não-disforia e de distensão, de modo que ele nega a transgressão, mas ainda não têm a integração totalmente afirmada.

Do ponto de vista do sujeito narrativo, o que temos então é a tentativa de encontrar um espaço literário, onde os valores vistos como transgressivos, possam ser abordados sem o crivo do preconceito e do julgamento pejorativo. Isso no poema, é acompanhado por uma dimensão passional. Surge, como já dissemos antes, em um tom de afronta, gerando uma espécie vingança que aparece em oposição à resignação, apresentado no verso parafraseado pelo dito popular: "vai ter que me engolir com casca e tudo!"'.

Essa citação nos adverte que ao invés de resignar-se com a situação de opressão, o enunciador, movido pela ira, procura resolver a disjunção com essa falta que lhe é imposta, punindo - daí a vingança - aquele quem ele toma como anti-sujeito; justamente pelo fato deste haver quebrado o contrato de fidúcia pressuposto. Ou seja, o enunciador, neste caso, representado pelo sujeito narrativo, empenha-se para tornar sua poesia aceita, colocando-se na posição de destinador-manipulador, levando o sujeito destinatário, manipulado provocativamente (Bem feito! Quem mandou me ler?), a reavaliar o seu conceito literário, de modo a perceber a competência do seu fazer poético, e sendo obrigado a engolir com "casca e tudo" o soneto, acabe no final, tendo seu julgamento suspenso.

Devemos sempre lembrar, que o mérito de um texto ser tomado como artístico ou um simples relato pessoal, depende do modo como ele é interpretado pelo público que o lê. Essa intersubjetividade é parte da noção semiótica de "contrato fiduciário", baseado nas expectativas e nos valores entre sujeitos. Em Teoria do discurso:fundamentos semióticos (Barros, 2001), a autora nos diz: "o enunciador coloca-se como destinador-manipulador, responsável pelos valores do discurso e capaz de levar o enunciatário, seu destinatário, a crer e a fazer".

Vimos até então que no plano de conteúdo, em nível fundamental, o poema segue o sentido de uma semântica, que apoia-se no conceito de transgressão vs. integração. Assim, do mesmo modo, no plano de expressão, devemos ter também descrito uma oposição sonora, uma vez que não estamos mais falando de conceitos, mas sim de som.

\subsection{Plano de Expressão}

Segundo os estudos da Fonologia, o plano de expressão linguiístico é constituído por vogais e consoantes. As vogais caracterizam-se pela posição central que ocupam na sílaba, e as consoantes pela posição periférica. Essas ocupações, na substância sonora, assumem o papel de som e ruído.

$\mathrm{Na}$ formação dos sons, portanto, as vogais devem formar ondas sonoras regulares, enquanto que as consoantes formam ondas sonoras irregulares. No entanto, entre o som e o ruído, ocorrem mais duas possibilidades de formação. Junto com a propriedade de formar sons, as vogais possuem um aspecto durativo que, além de participar da formação das vogais, participa também da formação de algumas consoantes. As semi-vogais estão no limite da transformação da articulação dos sons na 
articulação dos ruídos, na medida em que o som que são capazes de formar não ocupa o centro, mas as margens das sílabas na formação de ditongos e tritongos.

Assim, se pensarmos no quadrado semiótico e articularmos esses termos, teremos as vogais representando o valor de som, as semivogais os de não-som, e as consoantes oclusivas - pelo aspecto pontual - indicando ruído. Ao passo que, negando o ruído, vamos ter as consoantes constritivas, quer dizer, aquelas que se aproximam das vogais devido ao seu aspecto durativo.

Em Desforrado, o que temos é uma incidência das consoantes oclusivas, principalmente das fricativas ("converto o desabafo em verso agudo"). De modo que a regularidade métrica dos versos, acentuados sempre na quarta, oitava e décima sílabas, parece ligar-se com o aspecto pontual e intenso das consoantes, determinando, assim, o caráter rítmico do poema.

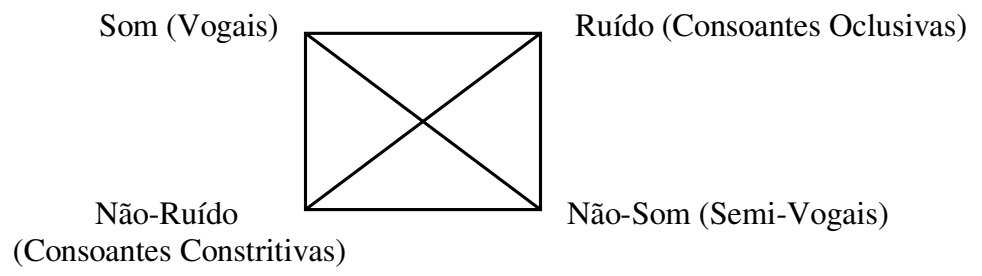

Dessa maneira, podemos tentar homologar sobre este modelo, baseando-se na hipótese de Wisnik ${ }^{1}$, uma categoria fundamental pautada na transgressão vs integração, onde o som é marcado pela idéia de conservação - possuindo um aspecto integrativo e predeterminado - e o ruído marcado pelo traço semântico da invenção - possuindo um aspecto polêmico e desintegrador ${ }^{2}$.

Assim, percebe-se que o poema é construído sonoramente a partir de uma estratégia que se apoia na transgressão (conforme já observamos no plano de conteúdo), uma vez que o ruído, de acordo com esse esquema, é o som que desorganiza.

Sabemos que no plano de conteúdo, o efeito de narratividade ocorre justamente pelas transformações juntivas, que, baseadas na manipulação e na paixão, faz com que sujeitos e objetos passem a se movimentar e a circular entre si, criando desta forma, o percurso: ação $\rightarrow$ manipulação $\rightarrow$ julgamento.

Embora no plano de expressão, não possamos justificar as transformações sonoras, tal qual no plano de conteúdo, essas, acabam se justificando em termos de ação e paixão, que é o que de fato, movimenta as transformações. Ao trabalhar com a

1 WISNICK, José Miguel. O som e o sentido. São Paulo, Cia das Letras, 1999 (p. 32-33).

2 Devemos observar, porém, que o conceito de som nem sempre é um dado absoluto, ele deve vir sempre relativizado culturalmente (o que para determinada cultura pode ser ruído para outra não é), assim o som pode ser muitas vezes originado pelo ruído (o que antes era visto como inesperado e chocante, passa a ser institucionalizado). 
semiótica da canção, L. Tatit elaborou um modelo cuja proposta foi demonstrar, basicamente, a existência de três tipos básicos de música: as passionais, com exploração melódica, em que as frases musicais estão distantes uma das outras, os intervalos são longos e o andamento é lento; as temáticas, que são rítmicas, com frases e intervalos musicais curtos, e de execução rápida; por fim, as figurativas, ou seja, aquelas canções mais próximas da maneira de falar do que de cantar.

Com esse modelo, é possível então estabelecer uma isomorfia entre os planos da linguagem, em que ritmo e melodia, são os responsáveis pela transformação sonora. Do mesmo modo que no plano de conteúdo, o efeito de ação se dá por meio da aquisição de competência do sujeito, por isso as frequientes trocas com os objetos modais; a paixão, por outro lado, é obtida não mais por esta aquisição, mas sim, quando o sujeito está envolvido com as suas próprias competências. Dessa maneira, dizemos que a paixão é mais melodiosa e a ação mais rítmica. Essa aproximação conceitual de sentido entre os dois planos, justifica-se, na medida em que tomamos o ritmo e a ação por um aspecto pontual; e melodia e paixão por um aspecto durativo.

Nesse sentido, em nível narrativo, o plano de expressão deste soneto, confirma aquilo que já havíamos verificado em nível fundamental, ou seja, trata-se de um poema que incide sobre o ritmo, ao invés de estar voltado para a melodia.

Até esse momento, nossa discussão limitou-se em analisar alguns fatores que nos ajudaram na compreensão do nível semio-narrativo. Tratamos dos valores gerados pela categoria semântica e na sua conversão em objeto de valor. Cabe agora, seguirmos com uma abordagem mais ampla, ao discutir o que acontece no nível discursivo.

Em Semiótica, tomamos o fato de existir um enunciador marcado no enunciado em primeira pessoa, como uma debreagem enunciativa. Essa é uma maneira do narrador criar no texto, os efeitos de subjetividade e aproximação. Embora saibamos que no soneto, o enunciador é ao mesmo tempo o narrador e também o autor, ainda assim, devemos dizer que quem enuncia é um "eu lírico" marcado nas desinências verbais de primeira pessoa, por exemplo, em "sou", "choro", "vendo", e no pronome possessivo "meu". Isso denota que sempre quando surge um enunciador na figura do $e u$, necessariamente, por oposição, há um enunciatário também marcado na figura do tu, como no trecho: (e os olhos dos leitores esbugalho).

Porém, aqui há um efeito de sentido no uso do substantivo "os leitores", que é uma terceira pessoa colocada no lugar da segunda, marcado também nos pronomes "lhe" e "quem" e nas formas imperativas que surgem no primeiro verso da segunda estrofe: "Bem feito!" (é o que se diz ao cego) "Chora!". O fato de tomar uma categoria no lugar da outra, chama-se embreagem. Neutraliza-se a diferença entre segunda e terceira pessoas, de modo que, a terceira é reconhecida como segunda. Quando o enunciador é marcado no enunciado, têm-se o efeito de subjetividade, pois surge uma referência as idéias e aos sentimentos pessoais; há nesse sentido uma aproximação entre enunciador e enunciatário: (Bem feito! Quem mandou me ler? Agora / vai ter que me engolir com casca e tudo!). Já o uso da terceira pessoa no lugar do tu, objetiva essa relação, promovendo um distanciamento entre os sujeitos: (E mesmo quando em parte me desnudo, / quem prova sente nojo e cospe fora.).

Figurativamente, encontramos a mesma relação de aproximação e distanciamento no uso dos verbos "engolir" e "cuspir". Quando o enunciador refere-se à 
própria poesia, ele emprega o termo "engolir", lexicalizando, metaforicamente, a aceitação do fazer poético. Ao passo que, quando se refere ao enunciatário, usa o verbo “cuspir”, para mostrar a não-aceitação desse fazer, e por conseguinte, sua rejeição. Concluindo, parece ficar claro então, que o soneto trabalha justamente com a idéia de aproximação e distanciamento, representado na relação $e u$-tu, confirmando, portanto, aquilo que vimos em nível fundamental e narrativo.

\section{REFERÊNCIAS BIBLIOGRÁFICAS}

BARROS, D.L.P. de (1990). Teoria semiótica do texto. São Paulo, Ática. (1988). Teoria do discurso: fundamentos semióticos. São Paulo, Atual.

(2003). Estudos do discurso. In. Introdução à lingüística II. FIORIN, J. L. São Paulo, Contexto. 209-211.

GREIMAS, A. (s.d.). Semântica estrutural. São Paulo, Ática.

HJELMSLEV, L. (1975). Prolegômenos a uma teoria da linguagem. São Paulo, Perspectiva.

MATTOSO, Glauco. (2004). Poesia Digesta. São Paulo, Landy.

TATIT, L. (2002). Análise Semiótica através das Letras. São Paulo, Ateliê Editorial.

\section{Como citar este artigo:}

ALONSO, Fabiano Garcia Baltazar da Silva; SILVA, Patrícia Amorim da. O conflito entre o plano de expressão e conteúdo na poesia de Glauco Mattoso. Estudos Semióticos, Número 2, São Paulo, 2006. Disponível em <www.fflch.usp.br/dl/semiotica/es > . Acesso em "dia/mês/ano". 